\title{
TERT rs2736098 (Ex2-659G>A) polymorphism and cancer susceptibility: evidence from a comprehensive meta-analysis
}

\author{
Tingyuan Pang ${ }^{1, *}$, Minjie Zhou ${ }^{2, *}$, Rumin Liu ${ }^{2}$, Jia Luo ${ }^{2}$ and Renfei Xia ${ }^{2}$ \\ ${ }^{1}$ Department of Pharmacy, Affiliated Cancer Hospital \& Institute of Guangzhou Medical University, Guangzhou City, 510000, \\ P.R. China \\ ${ }^{2}$ Department of Kidney Transplantation, Nanfang Hospital, Southern Medical University, Guangzhou City, 510000, P.R. China \\ *First author \\ \#Second author
}

Correspondence to: Renfei Xia, email: xiarf@smu.edu.cn

Keywords: TERT, rs2736098, polymorphism, cancer, meta-analysis

Received: August 18, 2017 Accepted: September 20, 2017

Published: October 09, 2017

Copyright: Pang et al. This is an open-access article distributed under the terms of the Creative Commons Attribution License 3.0 (CC BY

3.0), which permits unrestricted use, distribution, and reproduction in any medium, provided the original author and source are credited.

\section{ABSTRACT}

Increasing researches have been performed regarding the relationship between TERT rs2736098 and cancer risk, but no consensus has been reached about the relationship. Here, we conducted this updated meta-analysis, aiming to comprehensively evaluate the role of TERT rs2736098 in cancer risk. We systematically searched potential relevant articles through PubMed, EMBASE, CNKI, and WanFang database before August 2017. A total of 33 studies with 18685 cases and 23820 controls were finally included in the current meta-analysis. We then adopted odds ratios (ORs) and $95 \%$ confidence intervals (CIs) to analyze the contributions of TERT rs2736098 to cancer risk. We found that the TERT rs2736098 polymorphism was associated with risk of cancer in overall analysis (AA vs. GG: OR $=1.26,95 \%$ CI = 1.09-1.47; AA vs. AG/GG: OR = 1.22, 95\% CI = 1.09-1.36; AA/AG vs. GG: OR = $1.13,95 \% \mathrm{CI}=1.02-1.24$; $A$ vs. $G: \mathrm{OR}=1.11,95 \% \mathrm{CI}=1.04-1.20)$. Furthermore, in analysis stratified by cancer type, ethnicity, control source, quality score, and HardyWeinberg equilibrium (HWE) in controls, we found increased risk of cancer among lung cancer, bladder cancer, breast cancer, colorectal cancer, other cancers, Asians, hospital-based subgroup, score $>9$ group, as well as controls agreement with HWE group. Despite some limitations, the current meta-analysis represented the largest and the most comprehensive investigations, with the strongest conclusion than ever before. To further explicit the association between TERT rs2736098 and cancer risk, more well-design case-control studies with larger sample size are warranted in the future.

\section{INTRODUCTION}

Cancer is a substantial public health burden, with an estimate of 14.1 million new cancer cases and 8.2 million cancer-related deaths occurred globally [1]. Although progress has been achieved in understanding the etiology of carcinogenesis, the definitive etiology still remains not yet fully elucidated. Mounting evidences have suggested that cancer is a multifactorial disease caused by genetic and environmental interactions [2-4].

Telomerase is an RNA-dependent DNA polymerase containing two essential components, catalytic subunit with the reverse transcriptase activity and an essential structural RNA component with a sequence complementary to the telomere sequence [5]. TERT gene is located on the short (p) arm of chromosome 5 at position 15.33 (5p15.33), and composes of 16 exons $[6,7]$. TERT gene encodes the reverse transcriptase component of the telomerase, which is essential in maintaining the length of telomer [8]. In addition, telomerase is also responsible for chromosomal stability, and cellular immortality [9]. Telomeres might become shorter during mitosis due to incomplete replication of linear chromosomes by conventional DNA polymerases [10]. Normally, TERT mRNA is not expressed in most human somatic cells; however, aberrant expression 
of TERT mRNA and protein are associated with development of various cancers $[11,12]$.

More and more epidemiological studies were accessible regarding the association between the TERT rs2736098 polymorphism and cancer risk, yet conflicting conclusions remain. Besides, the latest meta-analysis was performed a year ago, which updated to March 2015. Nearly 10 new case-control studies with larger sample size were published since then. Thus, it is of great value to updated the meta-analysis regarding the association of interest. The current meta-analysis was the most comprehensive to date, which undoubtedly will shed some light on the current uncertain claims.

\section{RESULTS}

\section{Study characteristics}

A total of 144 potentially relevant publications were initially identified from the databases. After screening titles and abstracts, 106 publications were excluded because of their failure to reach inclusion criteria. The remaining 38 publications were further assessed through careful reading. We further excluded 8 publications based on the following reasons: 7 publications were meta-analyses [13-19], 1 was case only research [20]. 2 additional publications were further extracted by manually screening the references of the retrieval articles [21, 22]. As a result, 33 studies including 32 publications were used for investigation [13, 16, 21-50]. The general workflow of selecting the eligible studies was graphically shown in Figure 1.

In general, the current study contains 18685 cases and 23820 controls (Table 1). Studies were conducted on several cancer types, including lung cancer, bladder cancer, breast cancer, colorectal cancer, cervical cancer, glioma, hepatocellular carcinoma (HCC), oral squamous cell carcinoma (OSCC), acute lymphoblastic leukemia (ALL), renal cell carcinoma (RCC), squamous cell carcinoma of head and neck (SCCHN), pancreatic cancer, esophageal carcinoma. In terms of ethnicities, 23 studies focused on Asians and 10 on Caucasians. Of these, there were 24 hospital based and 9 population based data sets. 18 studies were categorized as low quality and 15 were high quality. The controls' genotype frequencies in agreement with Hardy-Weinberg equilibrium (HWE) was observed in 27 studies, while not available in 6 studies.

\section{Meta-analysis results}

We presented the detailed results of association between rs2736098 polymorphism and cancer risk in Table 2 and Figure 2. Overall, we detected significant association between rs 2736098 polymorphism and cancer risk among four genetic models (AA vs. GG: $\mathrm{OR}=1.26$, $95 \% \mathrm{CI}=1.09-1.47 ; \mathrm{AA}$ vs. $\mathrm{AG} / \mathrm{GG}: \mathrm{OR}=1.22,95 \%$ $\mathrm{CI}=1.09-1.36 ; \mathrm{AA} / \mathrm{AG}$ vs. $\mathrm{GG}: \mathrm{OR}=1.13,95 \% \mathrm{CI}=$ 1.02-1.24; A vs. G: $\mathrm{OR}=1.11,95 \% \mathrm{CI}=1.04-1.20$ ). Stratification analysis by cancer type revealed that statistically significantly increased risk was found among lung cancer, bladder cancer, breast cancer, colorectal cancer, and other cancers, but not HCC and SCCHN. Further subgroup analysis by ethnicity, a significantly increased cancer risk was observed in Asians in all genetic models, but not Caucasians. As to the subgroup of control source, only hospital-based subgroup could contribute to increase risk of cancer. When stratified by quality score,

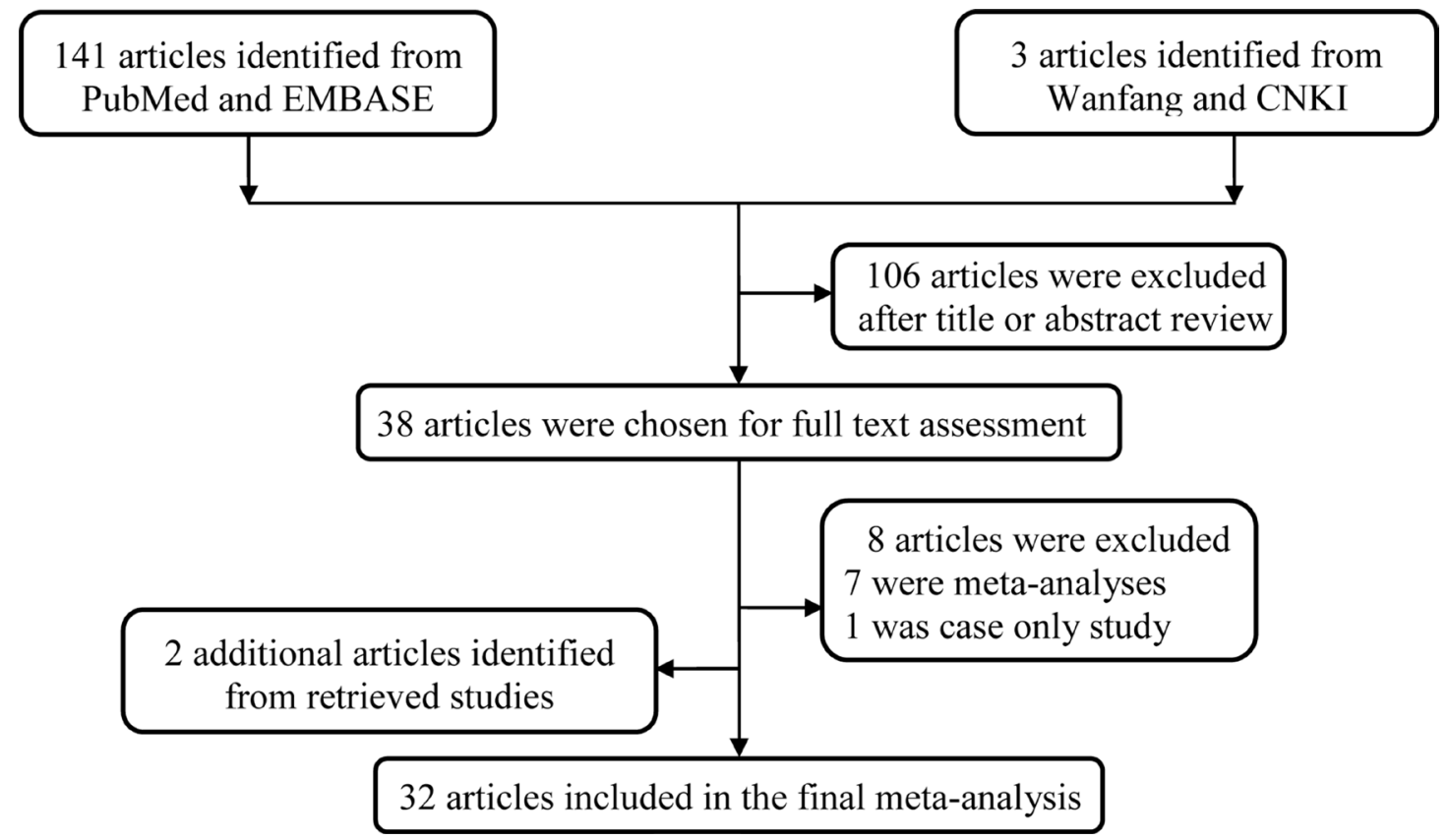

Figure 1: Flowchart of included studies. 
Table 1: Characteristics of studies included in the current meta-analysis

\begin{tabular}{|c|c|c|c|c|c|c|c|c|c|c|c|c|c|c|c|c|c|}
\hline \multirow[t]{2}{*}{ Surname } & \multirow[t]{2}{*}{ Year } & \multirow{2}{*}{$\begin{array}{c}\text { Cancer } \\
\text { type }\end{array}$} & \multirow[t]{2}{*}{ Country } & \multirow[t]{2}{*}{ Ethnicity } & \multirow{2}{*}{$\begin{array}{l}\text { Control } \\
\text { Source }\end{array}$} & \multirow{2}{*}{$\begin{array}{l}\text { Genotype } \\
\text { method }\end{array}$} & \multirow{2}{*}{$\begin{array}{c}\text { Genotype } \\
\text { quality }\end{array}$} & \multicolumn{4}{|c|}{ Case } & \multicolumn{4}{|c|}{ Control } & \multirow[t]{2}{*}{ HWE } & \multirow[t]{2}{*}{ Scor } \\
\hline & & & & & & & & GG & AG & $\mathbf{A A}$ & All & GG & AG & $\mathbf{A A}$ & All & & \\
\hline Savage & 2007 & Breast & Poland & Caucasian & PB & TaqMan & High & 1171 & 699 & 97 & 1967 & 1313 & 811 & 141 & 2265 & 0.294 & 13 \\
\hline Choi & 2009 & Lung & Korea & Asian & HB & PCR-RFLP & High & 311 & 322 & 87 & 720 & 345 & 320 & 55 & 720 & 0.101 & 11 \\
\hline Liu & 2010 & SCCHN & USA & Caucasian & $\mathrm{HB}$ & TaqMan & High & 588 & 419 & 72 & 1079 & 576 & 461 & 78 & 1115 & 0.271 & 11 \\
\hline Gago-Dominguez & 2011 & Bladder & USA & Caucasian & PB & TaqMan & High & 217 & 189 & 43 & 449 & 278 & 210 & 43 & 531 & 0.706 & 12 \\
\hline Gago-Dominguez & 2011 & Bladder & China & Asian & $\mathrm{PB}$ & TaqMan & High & 178 & 236 & 85 & 499 & 203 & 270 & 54 & 527 & 0.009 & 12 \\
\hline Ding & 2011 & $\mathrm{HCC}$ & China & Asian & $\mathrm{HB}$ & TaqMan & Low & 500 & 563 & 210 & 1273 & 526 & 604 & 198 & 1328 & 0.255 & 9 \\
\hline Chen & 2011 & Glioma & China & Asian & $\mathrm{HB}$ & MassARRAY & High & 351 & 461 & 141 & 953 & 430 & 486 & 117 & 1033 & 0.246 & 11 \\
\hline Liu & 2011 & SCCHN & USA & Caucasian & $\mathrm{HB}$ & TaqMan & Low & 481 & 351 & 56 & 888 & 468 & 356 & 61 & 885 & 0.546 & 9 \\
\hline $\mathrm{Xu}$ & 2012 & Gastric & China & Asian & $\mathrm{HB}$ & PCR-RFLP & High & 116 & 130 & 51 & 297 & 119 & 137 & 50 & 306 & 0.322 & 10 \\
\hline Hofer & 2012 & Colorectal & Austria & Caucasian & PB & TaqMan & High & 86 & 45 & 6 & 137 & 963 & 623 & 119 & 1705 & 0.186 & 12 \\
\hline Wang & 2012 & Cervical & China & Asian & $\mathrm{PB}$ & TaqMan & High & 375 & 444 & 174 & 993 & 397 & 480 & 138 & 1015 & 0.710 & 12 \\
\hline $\mathrm{Li}$ & 2013 & Lung & China & Asian & $\mathrm{HB}$ & TaqMan & High & 173 & 207 & 88 & 468 & 227 & 250 & 67 & 544 & 0.886 & 10 \\
\hline $\mathrm{Ma}$ & 2013 & Bladder & China & Asian & $\mathrm{PB}$ & MassARRAY & High & 71 & 75 & 28 & 174 & 373 & 461 & 127 & 961 & 0.408 & 12 \\
\hline Sheng & 2013 & ALL & China & Asian & PB & TaqMan & High & 236 & 238 & 93 & 567 & 276 & 298 & 96 & 670 & 0.286 & 14 \\
\hline $\mathrm{Wu}$ & 2013 & Lung & China & Asian & $\mathrm{HB}$ & TaqMan & Low & 205 & 232 & 102 & 539 & 263 & 278 & 86 & 627 & 0.361 & 8 \\
\hline Zhang & 2013 & $\mathrm{HCC}$ & China & Asian & $\mathrm{HB}$ & PCR-RFLP & Low & 133 & 206 & 61 & 400 & 177 & 158 & 65 & 400 & 0.004 & 9 \\
\hline Gao & 2014 & Lung & China & Asian & $\mathrm{HB}$ & MassARRAY & Low & 122 & 145 & 42 & 309 & 137 & 143 & 28 & 308 & 0.104 & 7 \\
\hline Hashemi & 2014 & Breast & Iran & Asian & $\mathrm{PB}$ & PCR-RFLP & Low & 72 & 140 & 40 & 252 & 51 & 113 & 58 & 222 & 0.777 & 7 \\
\hline Singh & 2014 & Bladder & India & Asian & $\mathrm{HB}$ & TaqMan & High & 77 & 106 & 42 & 225 & 117 & 95 & 28 & 240 & 0.203 & 9 \\
\hline $\mathrm{Su}$ & 2014 & $\mathrm{HCC}$ & China & Asian & $\mathrm{HB}$ & TaqMan & Low & 75 & 97 & 29 & 201 & 111 & 76 & 23 & 210 & 0.077 & 8 \\
\hline Yin & 2014 & Esophageal & China & Asian & $\mathrm{HB}$ & PCR & High & 245 & 277 & 78 & 600 & 270 & 306 & 75 & 651 & 0.403 & 11 \\
\hline Zhang & 2014 & Lung & China & Asian & $\mathrm{HB}$ & PCR & High & 135 & 173 & 58 & 366 & 157 & 171 & 36 & 364 & 0.283 & 10 \\
\hline Zhao & 2014 & Lung & China & Asian & $\mathrm{HB}$ & TaqMan & High & 337 & 438 & 177 & 952 & 406 & 443 & 106 & 955 & 0.365 & 12 \\
\hline Campa & 2015 & Pancreatic & Mixed & Caucasian & $\mathrm{PB}$ & TaqMan & Low & 980 & 584 & 126 & 1690 & 1839 & 1307 & 251 & 3397 & 0.372 & 9 \\
\hline Jannuzzi & 2015 & Colorectal & Turkey & Caucasian & $\mathrm{HB}$ & PCR-RFLP & Low & 25 & 14 & 65 & 104 & 15 & 28 & 92 & 135 & 0.000 & 9 \\
\hline Yoo & 2015 & Lung & Korea & Asian & $\mathrm{HB}$ & FIHP & Low & 499 & 465 & 130 & 1094 & 487 & 472 & 98 & 1057 & 0.283 & 9 \\
\hline De Martino & 2016 & $\mathrm{RCC}$ & Austria & Caucasian & $\mathrm{HB}$ & ES & Low & 24 & 123 & 92 & 239 & 121 & 151 & 94 & 366 & 0.001 & 5 \\
\hline Oztas & 2016 & Breast & Turkey & Caucasian & $\mathrm{HB}$ & PCR-RFLP & Low & 40 & 52 & 15 & 107 & 26 & 62 & 20 & 108 & 0.115 & 9 \\
\hline Xing & 2016 & Lung & China & Asian & $\mathrm{HB}$ & TaqMan & Low & 210 & 161 & 47 & 418 & 264 & 123 & 23 & 410 & 0.092 & 8 \\
\hline $\mathrm{Lu}$ & 2016 & Bladder & China & Asian & $\mathrm{HB}$ & PCR-RFLP & Low & 58 & 95 & 48 & 201 & 80 & 88 & 32 & 200 & 0.349 & 8 \\
\hline Carkic & 2016 & OSCC & Serbia & Caucasian & $\mathrm{HB}$ & PCR-RFLP & Low & 38 & 45 & 7 & 90 & 15 & 73 & 12 & 100 & 0.000 & 6 \\
\hline Xiao & 2017 & Lung & China & Asian & $\mathrm{HB}$ & TaqMan & Low & 78 & 95 & 30 & 203 & 123 & 77 & 25 & 225 & 0.020 & 7 \\
\hline Yuan & 2017 & $\mathrm{HCC}$ & China & Asian & HB & TaqMan & Low & 85 & 127 & 19 & 231 & 94 & 115 & 31 & 240 & 0.650 & 7 \\
\hline
\end{tabular}

HWE, Hardy-Weinberg equilibrium; OSCC, oral squamous cell carcinoma; RCC, renal cell carcinoma; SCCHN, squamous cell carcinoma of head and neck; HCC, hepatocellular carcinoma; ALL, acute lymphoblastic leukemia; PB, population based; HB, hospital based; PCR, polymerase chain reaction; PCR-RFLP, polymerase chain reaction-restriction fragment length polymorphism; FIHP, Fluorescence-labeled hybridization probes; ES, electrophoretic separation.

significantly increased risk was observed in the score $>9$ group, but not $\leq 9$ group. We also observed significantly increased risk in subgroup of those SNP of controls agreement with HWE in all genetic models tested (AA vs. GG: $\mathrm{OR}=1.25,95 \% \mathrm{CI}=1.08-1.43$; AA vs. $\mathrm{AG} / \mathrm{GG}$ : OR $=1.21,95 \% \mathrm{CI}=1.08-1.36 ; \mathrm{AA} / \mathrm{AG}$ vs. $\mathrm{GG}: \mathrm{OR}=1.10$, $95 \% \mathrm{CI}=1.01-1.19$; A vs. $\mathrm{G}$ : $\mathrm{OR}=1.10,95 \% \mathrm{CI}=1.03-$ 1.18 ), with the exception of the heterozygote comparison.

\section{Heterogeneity and sensitivity analysis}

We first conducted $Q$ test and $I^{2}$ statistics to test between-study heterogeneity. Heterogeneity was indicated among all five genetic models as $P<0.001$. Thus, the random-effect model was employed to generate wider CIs. As to the sensitivity analysis, the leaving each study out strategy showed that no substantial changes in ORs were observed after omitting each study (Figure 3). This reflects the stability and reliability of this meta-analysis.

\section{Publication bias}

In Begg's funnel plots, we could not detect any obvious asymmetrical shape (Figure 4). Moreover, Egger's test result also revealed no evidence of publication bias among the studies (AA vs. GG: $P=0.92$; AG vs. 
GG: $P=0.16$; AA vs. AG $+\mathrm{GG}: P=0.52 ; \mathrm{AA}+\mathrm{AG}$ vs. GG: $P=0.16$; and A vs. G: $P=0.34)$.

\section{DISCUSSION}

In this meta-analysis, we attempted to settle down the debate about the role of TERT rs2736098 in cancer risk. The obtained results suggested that there exists a significant relationship between TERT rs2736098 and cancer risk. To the best of our knowledge, this updated meta-analysis involves the largest samples and the most convincing conclusions.

Numerous studies have investigated the role of TERT gene rs 2746098 polymorphism in the contributions to cancer risk. To obtain a clear association between TERT rs2736098 and cancer risk, several meta-analyses have been performed. The first meta-analysis was conducted by Zhang et al. [14] in 2012, with 8 studies consisting of 8,070 cases and 10,239 controls. They claimed that no significant association was observed between TERT

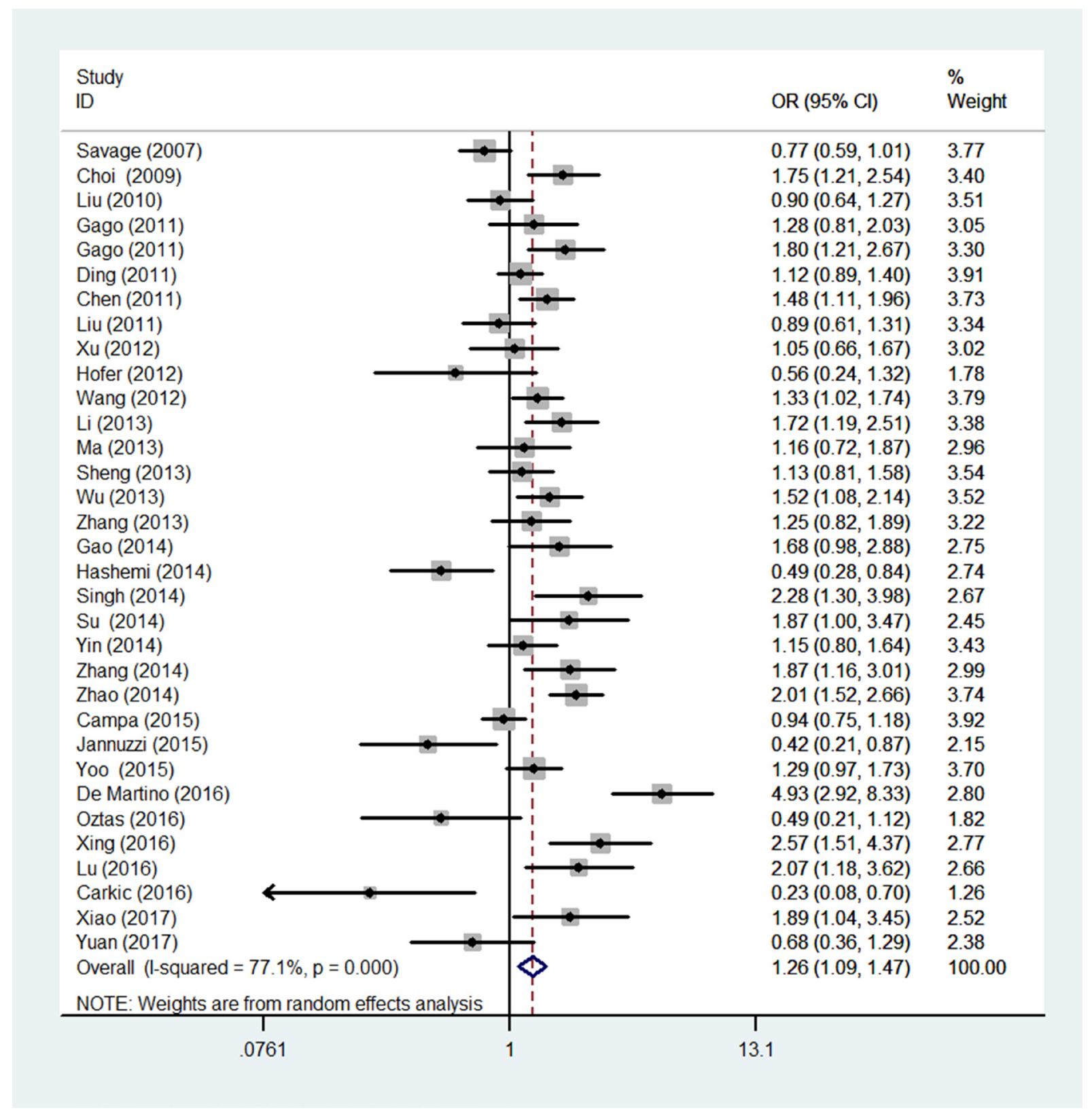

Figure 2: Forest plot of TERT rs2736098 polymorphism and overall cancer susceptibility (allele comparison model). The horizontal lines represent the study-specific ORs and 95\% CIs, respectively. The diamond represents the pooled results of OR and $95 \%$ CI. The random effect model generates a constant from the homogeneity statistic Cochran's Q and using this and other study parameters a random effects variance component is generated. The inverse of the sampling variance plus this constant that represents the variability across the population effects is then used as the weight. 
Table 2: Meta-analysis of the association between TERT rs2736098 polymorphism and overall cancer risk

\begin{tabular}{|c|c|c|c|c|c|c|c|c|c|c|c|}
\hline \multirow[t]{3}{*}{ Variables } & \multirow{3}{*}{$\begin{array}{l}\text { No. of } \\
\text { studies }\end{array}$} & \multicolumn{2}{|l|}{ Homozygous } & \multirow{2}{*}{$\begin{array}{c}\text { Heterozygous } \\
\text { AG vs. GG }\end{array}$} & \multirow[b]{3}{*}{$P$ het } & \multirow{3}{*}{$\begin{array}{c}\text { Recessive } \\
\text { AA vs. AG/GG } \\
\text { OR }(95 \% \text { CI })\end{array}$} & \multirow[b]{3}{*}{$P$ het } & \multirow{3}{*}{$\begin{array}{c}\text { Dominant } \\
\text { AA/AG vs. GG } \\
\text { OR }(95 \% \text { CI })\end{array}$} & \multirow[b]{3}{*}{$P$ het } & \multirow{2}{*}{\multicolumn{2}{|c|}{$\begin{array}{c}\text { Allele } \\
\text { A vs. G }\end{array}$}} \\
\hline & & \multicolumn{2}{|l|}{ AA vs. GG } & & & & & & & & \\
\hline & & OR $(95 \%$ CI $)$ & $P$ het & OR $(95 \%$ CI $)$ & & & & & & OR $(95 \%$ CI $)$ & $P$ het \\
\hline $\mathrm{All}^{\mathrm{a}}$ & 33 & $1.26(1.09-1.47)$ & $<0.001$ & $1.09(0.99-1.19)$ & $<0.001$ & $1.22(1.09-1.36)$ & $<0.001$ & $1.13(1.02-1.24)$ & $<0.001$ & $1.11(1.04-1.20)$ & $<0.001$ \\
\hline \multicolumn{12}{|l|}{ Cancer type } \\
\hline Lung & 9 & $1.71(1.51-1.94)$ & 0.453 & $1.18(1.05-1.34)$ & 0.037 & $1.60(1.42-1.80)$ & 0.783 & $1.29(1.14-1.46)$ & 0.021 & $1.29(1.18-1.41)$ & 0.033 \\
\hline Bladder & 5 & $1.62(1.27-2.08)$ & 0.258 & $1.17(0.93-1.45)$ & 0.068 & $1.52(1.24-1.85)$ & 0.569 & $1.26(1.01-1.57)$ & 0.045 & $1.25(1.08-1.45)$ & 0.086 \\
\hline $\mathrm{HCC}$ & 4 & $1.16(0.87-1.54)$ & 0.161 & $1.38(0.97-1.95)$ & 0.001 & $1.01(0.78-1.30)$ & 0.181 & $1.33(0.98-1.79)$ & 0.004 & $1.15(0.97-1.36)$ & 0.040 \\
\hline Breast & 3 & $0.64(0.46-0.89)$ & 0.235 & $0.87(0.68-1.13)$ & 0.194 & $0.71(0.57-0.88)$ & 0.361 & $0.80(0.59-1.07)$ & 0.117 & $0.82(0.67-0.99)$ & 0.107 \\
\hline SCCHN & 2 & $0.90(0.70-1.16)$ & 0.963 & $0.92(0.81-1.05)$ & 0.577 & $0.93(0.73-1.20)$ & 0.862 & $0.92(0.81-1.04)$ & 0.627 & $0.94(0.85-1.03)$ & 0.751 \\
\hline Colorectal & 2 & $0.48(0.28-0.83)$ & 0.611 & $0.54(0.21-1.40)$ & 0.047 & $0.73(0.46-1.14)$ & 0.630 & $0.59(0.31-1.12)$ & 0.097 & $0.72(0.56-0.92)$ & 0.371 \\
\hline Others & 8 & $1.26(0.92-1.73)$ & $<0.001$ & $1.02(0.80-1.30)$ & $<0.001$ & $1.23(1.06-1.42)$ & 0.121 & $1.06(0.83-1.36)$ & $<0.001$ & $1.08(0.91-1.27)$ & $<0.001$ \\
\hline \multicolumn{12}{|l|}{ Ethnicity } \\
\hline Asians & 23 & $1.43(1.26-1.63)$ & $<0.001$ & $1.15(1.05-1.25)$ & $<0.001$ & $1.33(1.19-1.50)$ & 0.001 & $1.21(1.11-1.32)$ & $<0.001$ & $1.19(1.12-1.27)$ & $<0.001$ \\
\hline Caucasians & 10 & $0.88(0.61-1.25)$ & $<0.001$ & $0.90(0.72-1.11)$ & $<0.001$ & $0.97(0.80-1.17)$ & 0.024 & $0.90(0.72-1.11)$ & $<0.001$ & $0.93(0.80-1.08)$ & $<0.001$ \\
\hline \multicolumn{12}{|c|}{ Source of control } \\
\hline $\mathrm{HB}$ & 24 & $1.38(1.16-1.65)$ & $<0.001$ & $1.16(1.02-1.31)$ & $<0.001$ & $1.29(1.15-1.50)$ & 0.001 & $1.20(1.06-1.37)$ & $<0.001$ & $1.17(1.07-1.28)$ & $<0.001$ \\
\hline PB & 9 & $1.03(0.82-1.29)$ & $<0.001$ & $0.93(0.87-0.99)$ & 0.549 & $1.05(0.85-1.31)$ & $<0.001$ & $0.96(0.88-1.04)$ & 0.164 & $0.99(0.90-1.09)$ & 0.002 \\
\hline \multicolumn{12}{|l|}{ Quality score } \\
\hline$>9$ & 15 & $1.30(1.10-1.54)$ & $<0.001$ & $1.02(0.96-1.08)$ & 0.530 & $1.29(1.11-1.49)$ & 0.001 & $1.07(0.99-1.16)$ & 0.021 & $1.10(1.02-1.19)$ & $<0.001$ \\
\hline$\leq 9$ & 18 & $1.23(0.96-1.57)$ & $<0.001$ & $1.15(0.96-1.39)$ & $<0.001$ & $1.15(0.98-1.35)$ & $<0.001$ & $1.17(0.97-1.41)$ & $<0.001$ & $1.12(0.99-1.28)$ & $<0.001$ \\
\hline \multicolumn{12}{|c|}{ HWE in controls } \\
\hline Yes & 27 & $1.25(1.08-1.43)$ & $<0.001$ & $1.05(0.98-1.12)$ & $<0.001$ & $1.21(1.08-1.36)$ & $<0.001$ & $1.10(1.01-1.19)$ & $<0.001$ & $1.10(1.03-1.18)$ & $<0.001$ \\
\hline No & 6 & $1.23(0.62-2.44)$ & $<0.001$ & $1.08(0.58-2.02)$ & $<0.001$ & $1.22(0.87-1.71)$ & 0.009 & $1.13(0.62-2.04)$ & $<0.001$ & $1.12(0.80-1.56)$ & $<0.001$ \\
\hline
\end{tabular}

HWE, Hardy-Weinberg equilibrium; Het, heterogeneity; HCC, hepatocellular carcinoma; SCCHN, squamous cell carcinoma of head and neck; HB, hospital based; PB, population based.

rs2736098 polymorphism and overall cancer risk. However, after stratified by ethnicity, a significantly increased risk of cancers was shown Among Asians. In another meta-analysis with 12 studies including 10044 cases and 12480 controls. Wu et al. [16] found that there was a borderline significant increased overall cancer risk conferred by rs2736098. In addition, such increased cancer risk was more obvious among lung cancer, bladder cancer, hospital-base design and Asians. The most recent published meta-analysis included 19 studies with 12520 cases and 14968 controls [18]. They found that GA/AA variant could contribute to increased risk of overall cancer. Their stratification analysis revealed that such association was more significant in Asians, lung cancer and hepatocellular carcinoma. It is obvious that conflict conclusions still exist, due to the relative small sample size included.

As several new studies have been updated since the latest meta-analysis, it is necessary for us to incorporate all the accessible studies to better elucidate the association between TERT rs2736098 polymorphism and cancer risk. In all, we found a significant relationship between TERT rs 2736098 and cancer risk in the pooled analysis under all the five-genetic model, except for heterozygous model. Such findings were consistent with the results reported in the study of Wu et al. [16] and the latest metaanalysis [18]. Subgroup analysis by ethnicity suggested that individuals carrying TERT rs2736098 polymorphism from Asians but not among Europeans were more likely to exhibit an increased cancer risk, possibly because of the differences in genetic backgrounds among different populations. Our results suggested that genetic variants in TERT significantly increased the risk of lung cancer, bladder cancer, breast cancer, colorectal cancer and other cancer, but not HCC and SCCHN. These lines of evidence suggested that TERT rs 2736098 polymorphism may have different effects in different cancer types. The possible reasons for discrepancies regarding cancer susceptibility may be ascribed to tumor specificity, differences in ethnicity, and variations in sample sizes included in each investigation.

To improve the quality of the current metaanalysis, we adopted some measurements below. First, our meta-analysis was the first to search literatures from both English and Chinese, with the aim to strengthen the reliability of our conclusions. Second, we adopted sensitivity analysis and publication bias assay, and the results indicated that the conclusions are robust and no publication bias was detected.

Yet, some limitations still exist and thus cautions are needed before interpreting the results obtained from the current meta-analysis. First, the number of included studies is far from enough to obtain a robust conclusion, 


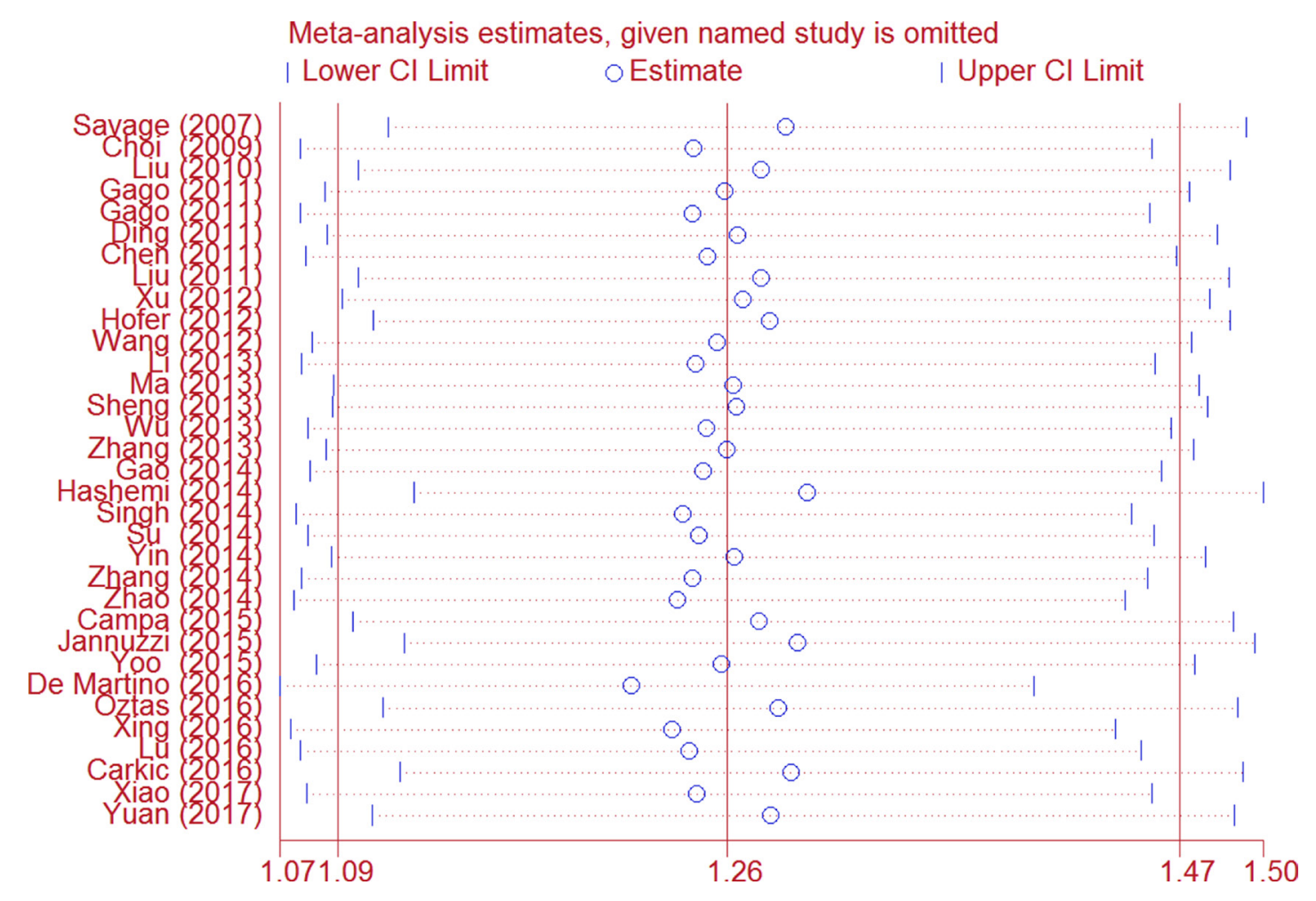

Figure 3: Sensitivity analysis of the association between TERT rs2736098 and cancer risk (allele comparison model). Each point represents the recalculated OR after omitting a separate study.

Begg's funnel plot with pseudo $95 \%$ confidence limits

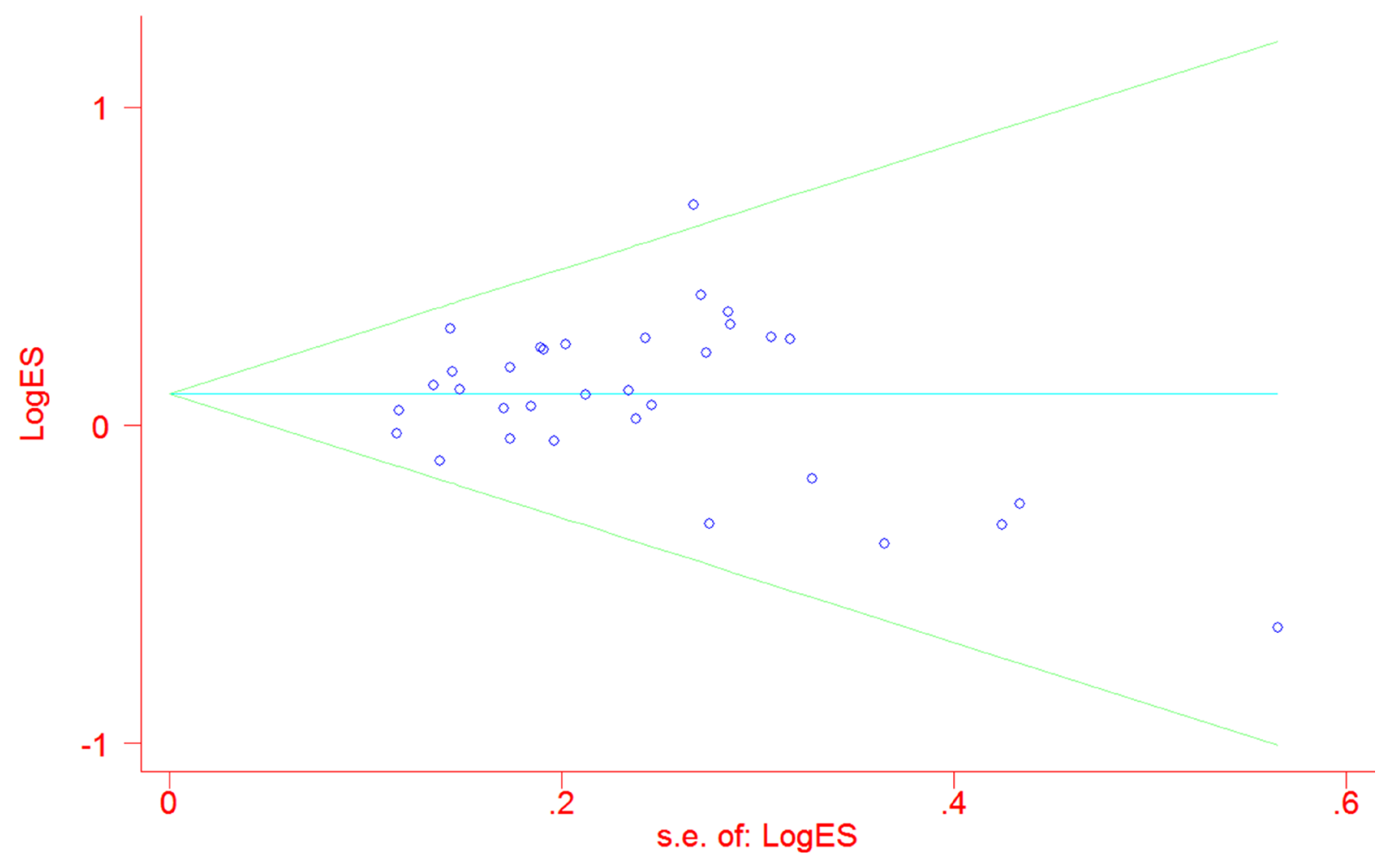

Figure 4: Funnel plot analysis to evaluate publication bias for TERT rs2736098 polymorphism (allele comparison model). Each point represents a separate study. 
especially for stratified analysis. Second, the validity of conclusion might be discount as significant between-study heterogeneity was observed in some comparisons. Third, we only calculated the crude ORs, but not the adjusted ORs, due to the lack of other important information like environmental factors, age, drinking status, and geneenvironment interactions. Fourth, selection bias could not be avoided, as only the studies written in English or Chinese were extracted. Last, nearly all the eligible casecontrol studies included were conducted among Asians and Caucasians, other ethnicities such as Africans were not undertaken. Concerning genetic and geographical differences, additional studies are needed to further confirm such conclusion from other ethnicities, especially Africans.

To sum up, the current meta-analysis provides a powerful evidence that TERT rs2736098 polymorphism is associated with cancer risk, from the perspective of the formed case-control studies. However, it is still needed for us to continue providing more new evidence based on large sample size, multi-center investigation case-control studies.

\section{MATERIALS AND METHODS}

\section{Publication search}

A comprehensive literature search was first conducted in English electronic database PubMed and EMBASE using the combination of the following items: "polymorphism or single nucleotide polymorphism or SNP or variant" and "TERT or hTERT or rs2736098 or telomere reverse transcriptase", and "cancer or neoplasm or tumor or carcinoma". Then we further expanded the searching field to Chinese database China National Knowledge Infrastructure (CNKI) and Wanfang database using the same combination items in Chinese. The searching time was updated to August 2017. Moreover, we also included the eligible studies extracted from the references of retrieved articles. A single study would be treated as separate studies if two more ethnic subpopulations is included. Only the largest or the latest study was included if there exist two more articles with overlapping data. No language publication restrictions were set in this searching strategy. The designation and writing of this meta-analysis was under the guidelines of Preferred Reporting Items for Systematic Reviews and Meta-analyses.

\section{Eligibility criteria}

In the current meta-analysis, only the studies met the following criteria were included: (1) studies published in English or Chinese; (2) unrelated case-control studies; (3) tested for the association of TERT rs2736098 polymorphism with cancer risk; (4) enough information to calculate odds ratios (ORs) and 95\% confidence intervals (CIs). Studies that failed to meet the above criteria were excluded in the final analysis.

\section{Data extraction}

We arranged two authors (Tingyuan and Minjie) to screen the articles and extracted available data from all eligible studies, blindly. The data shown below were extracted: first author's surname, publication year, country, ethnicity, the source of controls, genotyping methods, quality score, and numbers of cases and controls with AA, AG and GG genotypes. Any discrepancy was resolved after full discussion.

\section{Quality assessment}

To strengthen the robustness of our meta-analysis, a quality assessment was performed to all the included studies through adopting the quality assessment criteria (Supplementary Table 1). In brief, the quality scores range from 0 to 15. The studies with a score less than 9 were classified as low quality, while those more than 9 were classified as high quality.

\section{Statistical methods}

We first adopted goodness-of-fit $\chi^{2}$ test to assess whether the SNP in the control was departure from HWE. The strength of the association between TERT rs 2736098 polymorphism and overall cancers risk was measured by calculating crude ORs and their 95\% CIs using all five genetic models: homozygous model (AA vs. GG), heterozygous model (AG vs. GG), recessive model (AA vs. $A G+G G)$, dominant model (AA + AG vs. GG) and allele comparison (A vs. G). Stratification analyses were also performed by ethnicity, and source of control, quality score, and HWE in controls. Between-study heterogeneity was analyzed by the Cochran's $Q$ test and quantified by $I^{2}$ statistics. When homogeneity existed, the fixed model (Mantel-Haenszel method) was used to calculate the summary ORs and 95\% CIs; otherwise, the randomeffects model (the DerSimonian and Laird method) was utilized. Sensitivity analysis was done by individually removing studies one by one and reanalyzing the pooled risk estimates. Publication bias was further assessed using Begg's funnel plot and Egger's linear regression, with that asymmetric plot and a $P$ value $<0.05$ indicating the presence of publication bias. All statistical analysis was completed using STATA software (Stata Corporation, College Station, TX; version 11.0). All the statistics were two-sided with significant findings set at a $P$ value of $<$ 0.05 .

\section{CONFLICTS OF INTEREST}

The authors have declared that no competing interests exist. 


\section{FUNDING}

This study was supported by grants from Dean's Foundation of Nanfang Hospital of Southern Medical University (no. 2016C007).

\section{REFERENCES}

1. Siegel RL, Miller KD, Jemal A. Cancer statistics, 2016. CA Cancer J Clin. 2016; 66:7-30.

2. Pharoah PD, Dunning AM, Ponder BA, Easton DF. Association studies for finding cancer-susceptibility genetic variants. Nat Rev Cancer. 2004; 4:850-860.

3. Foulkes WD. Inherited susceptibility to common cancers. N Engl J Med. 2008; 359:2143-2153.

4. Fu W, Zhuo ZJ, Jia W, Zhu J, Zhu SB, Lin ZF, Wang FH, Xia H, He J, Liu GC. Association between TP53 gene Arg72Pro polymorphism and Wilms' tumor risk in a Chinese population. Onco Targets Ther. 2017; 10:1149-1154.

5. Calado RT, Young NS. Telomere diseases. N Engl J Med. 2009; 361:2353-2365.

6. Ozturk MB, Li Y, Tergaonkar V. Current Insights to Regulation and Role of Telomerase in Human Diseases. Antioxidants (Basel). 2017; 6:e17.

7. Harley CB. Telomerase and cancer therapeutics. Nat Rev Cancer. 2008; 8:167-179.

8. Stewart JA, Chaiken MF, Wang F, Price CM. Maintaining the end: roles of telomere proteins in end-protection, telomere replication and length regulation. Mutat Res. 2012; 730:12-19.

9. Engelhardt M, Martens UM. The implication of telomerase activity and telomere stability for replicative aging and cellular immortality (Review). Oncol Rep. 1998; 5:1043-1052.

10. Izumiyama-Shimomura N, Nakamura K, Aida J, Ishikawa N, Kuroiwa M, Hiraishi N, Fujiwara M, Ishikawa Y, Inoshita N, Yonese J, Matsuura M, Poon SS, Arai T, Takubo K. Short telomeres and chromosome instability prior to histologic malignant progression and cytogenetic aneuploidy in papillary urothelial neoplasms. Urol Oncol. 2014; 32:135-145.

11. Baird DM. Variation at the TERT locus and predisposition for cancer. Expert Rev Mol Med. 2010; 12:e16.

12. Aschacher T, Wolf B, Enzmann F, Kienzl P, Messner B, Sampl S, Svoboda M, Mechtcheriakova D, Holzmann $\mathrm{K}$, Bergmann M. LINE-1 induces hTERT and ensures telomere maintenance in tumour cell lines. Oncogene. 2016; 35:94-104.

13. Liu Z, Ma H, Wei S, Li G, Sturgis EM, Wei Q. Telomere length and TERT functional polymorphisms are not associated with risk of squamous cell carcinoma of the head and neck. Cancer Epidemiol Biomarkers Prev. 2011; 20:2642-2645.

14. Zhang XJ, Xu Z, Gong YL, Tang CJ, Chen JF. Association of TERT rs2736098 polymorphism with cancer risk: a metaanalysis. Asian Pac J Cancer Prev. 2012; 13:4943-4946.
15. Li C, Yin Z, Wu W, Li X, Zhou B. Genetic variants in TERTCLPTM1L genetic region associated with several types of cancer: a meta-analysis. Gene. 2013; 526:390-399.

16. Wu H, Qiao N, Wang Y, Jiang M, Wang S, Wang C, Hu L. Association between the telomerase reverse transcriptase (TERT) rs2736098 polymorphism and cancer risk: evidence from a case-control study of non-small-cell lung cancer and a meta-analysis. PLoS One. 2013; 8:e76372.

17. Yang Z, Zhang X, Fang S, Tan Y, Yan H, Gu W, Wang J. Increased risk of developing lung cancer in Asian patients carrying the TERT rs2736098 $\mathrm{G}>\mathrm{A}$ polymorphism: evidence from 3,354 cases and 3,518 controls. Onco Targets Ther. 2015; 8:2757-2765.

18. Li T, Xian Y, Tian T, Zhuang X, Chu M. New evidence of TERT rs2736098 polymorphism and cancer risk: an updated meta-analysis. J BUON. 2016; 21:491-497.

19. Li ZY, Dong YL, Feng Y, Zhang Z, Cao XZ. Polymorphisms in the telomerase reverse transcriptase promoter are associated with risk of breast cancer: A meta-analysis. J Cancer Res Ther. 2016; 12:1040-1044.

20. Li JJ, Zheng PCJ, Wang YZ. The correlations between DNA methylation and polymorphisms in the promoter region of the human telomerase reverse transcriptase (hTERT) gene with postoperative recurrence in patients with thyroid carcinoma (TC). World J Surg Oncol. 2017; 15:114.

21. Gago-Dominguez M, Jiang X, Conti DV, Castelao JE, Stern MC, Cortessis VK, Pike MC, Xiang YB, Gao YT, Yuan JM, Van Den Berg DJ. Genetic variations on chromosomes 5 p15 and $15 \mathrm{q} 25$ and bladder cancer risk: findings from the Los Angeles-Shanghai bladder case-control study. Carcinogenesis. 2010; 32:5.

22. Xu BH, Si JL, Qi YQ, Cui WL. Association of genetic polymorphism of TERT with susceptibility to gastric cancer. Chinese Clinical Oncology. 2012; 17:4.

23. Savage SA, Chanock SJ, Lissowska J, Brinton LA, Richesson D, Peplonska B, Bardin-Mikolajczak A, Zatonski W, Szeszenia-Dabrowska N, Garcia-Closas M. Genetic variation in five genes important in telomere biology and risk for breast cancer. Br J Cancer. 2007; 97:832-836.

24. Choi JE, Kang HG, Jang JS, Choi YY, Kim MJ, Kim JS, Jeon HS, Lee WK, Cha SI, Kim CH, Kam S, Jung TH, Park JY. Polymorphisms in telomere maintenance genes and risk of lung cancer. Cancer Epidemiol Biomarkers Prev. 2009; 18:2773-2781.

25. Liu Z, Li G, Wei S, Niu J, Wang LE, Sturgis EM, Wei Q. Genetic variations in TERT-CLPTM1L genes and risk of squamous cell carcinoma of the head and neck. Carcinogenesis. 2010; 31:1977-1981.

26. Chen H, Chen Y, Zhao Y, Fan W, Zhou K, Liu Y, Zhou L, Mao Y, Wei Q, Xu J, Lu D. Association of sequence variants on chromosomes 20,11, and 5 (20q13.33, 11q23.3, and 5 p15.33) with glioma susceptibility in a Chinese population. Am J Epidemiol. 2011; 173:915-922. 
27. Ding CY, Hu LM, Hu ZB, Shen HB. [The relationship between gene polymorphism of telomerase reverse transcriptase and susceptibility to hepatocellular carcinoma]. [Article in Chinese]. Zhonghua Yu Fang Yi Xue Za Zhi. 2011; 45:593-596.

28. Hofer P, Baierl A, Bernhart K, Leeb G, Mach K, Micksche $\mathrm{M}$, Gsur A. Association of genetic variants of human telomerase with colorectal polyps and colorectal cancer risk. Mol Carcinog. 2012; 51:E176-182.

29. Wang S, Wu J, Hu L, Ding C, Kan Y, Shen Y, Chen X, Shen H, Guo X, Hu Z. Common genetic variants in TERT contribute to risk of cervical cancer in a Chinese population. Mol Carcinog. 2012; 51:E118-122.

30. Li C, Yin Z, Wu W, Li X, Ren Y, Zhou B. Genetic variations in TERT-CLPTM1L genes and risk of lung cancer in Chinese women nonsmokers. PLoS One. 2013; 8:e64988.

31. Ma Z, Hu Q, Chen Z, Tao S, Macnamara L, Kim ST, Tian L, Xu K, Ding Q, Zheng SL, Sun J, Xia G, Xu J. Systematic evaluation of bladder cancer risk-associated singlenucleotide polymorphisms in a Chinese population. Mol Carcinog. 2013; 52:916-921.

32. Sheng X, Tong N, Tao G, Luo D, Wang M, Fang Y, Li J, $\mathrm{Xu} \mathrm{M}$, Zhang Z, Wu D. TERT polymorphisms modify the risk of acute lymphoblastic leukemia in Chinese children. Carcinogenesis. 2013; 34:228-235.

33. Zhang C, Tian YP, Wang Y, Guo FH, Qin JF, Ni H. hTERT rs2736098 genetic variants and susceptibility of hepatocellular carcinoma in the Chinese population: a case-control study. Hepatobiliary Pancreat Dis Int. 2013; 12:74-79.

34. Gao L, Thakur A, Liang Y, Zhang S, Wang T, Chen T, Meng J, Wang L, Wu F, Jin T, Li X, Liu JJ, Chen C, Chen M. Polymorphisms in the TERT gene are associated with lung cancer risk in the Chinese Han population. Eur J Cancer Prev. 2014; 23:497-501.

35. Hashemi M, Amininia S, Ebrahimi M, Hashemi SM, Taheri M, Ghavami S. Association between hTERT polymorphisms and the risk of breast cancer in a sample of Southeast Iranian population. BMC Res Notes. 2014; 7:895.

36. Singh V, Jaiswal PK, Mittal RD. Replicative study of GWAS TP63C/T, TERTC/T, and SLC14A1C/T with susceptibility to bladder cancer in North Indians. Urol Oncol. 2014; 32:1209-1214.

37. Su LY, Li XL, Shen L, Zhang Y, Zhao MM, Yin ZH, Su HY, Zhou BS. Polymorphisms of TERT and CLPTM1L and the risk of hepatocellular carcinoma in Chinese males. Asian Pac J Cancer Prev. 2014; 15:8197-8201.

38. Yin J, Wang L, Zheng L, Wang X, Shi Y, Shao A, Ding G, Liu C, Chen S, Tang W, Gu H. TERT-CLPTM1L Rs401681 $\mathrm{C}>\mathrm{T}$ polymorphism was associated with a decreased risk of esophageal cancer in a Chinese population. PLoS One. 2014; 9:e100667.

39. Zhang Y, Zhao M, Shen L, Ren Y, Su L, Li X, Yin Z, Zhou B. Genetic polymorphisms of TERT and CLPTM1L and risk of lung cancer: a case-control study in northeast Chinese male population. Med Oncol. 2014; 31:18.

40. Zhao MM, Zhang Y, Shen L, Ren YW, Li XL, Yin ZH, Zhou BS. Genetic variations in TERT-CLPTM1L genes and risk of lung cancer in a Chinese population. Asian Pac J Cancer Prev. 2014; 15:2809-2813.

41. Campa D, Rizzato C, Stolzenberg-Solomon R, Pacetti P, Vodicka P, Cleary SP, Capurso G, Bueno-de-Mesquita HB, Werner J, Gazouli M, Butterbach K, Ivanauskas A, Giese $\mathrm{N}$, et al. TERT gene harbors multiple variants associated with pancreatic cancer susceptibility. Int J Cancer. 2015; 137:2175-2183.

42. Jannuzzi AT, Karaman E, Oztas E, Yanar HT, Ozhan G. Telomerase Reverse Transcriptase (TERT) Gene Variations and Susceptibility of Colorectal Cancer. Genet Test Mol Biomarkers. 2015; 19:692-697.

43. Yoo SS, Do SK, Choi JE, Lee SY, Lee J, Cha SI, Kim CH, Park JY. TERT Polymorphism rs2853669 Influences on Lung Cancer Risk in the Korean Population. J Korean Med Sci. 2015; 30:1423-1428.

44. Lu BD, Liu DY, Yu ZY, Fu WJ, Chen JW, Lu HY. Association between genetic polymorphism of TERT and CLK3 with susceptibility of bladder cancer. J Pract Med. 2016; 32:4.

45. de Martino M, Taus C, Lucca I, Hofbauer SL, Haitel A, Shariat SF, Klatte T. Association of human telomerase reverse transcriptase gene polymorphisms, serum levels, and telomere length with renal cell carcinoma risk and pathology. Mol Carcinog. 2016; 55:1458-1466.

46. Carkic J, Nikolic N, Radojevic-Skodric S, KuzmanovicPficer J, Brajovic G, Antunovic M, Milasin J, Popovic B. The role of TERT-CLPTM1L SNPs, hTERT expression and telomere length in the pathogenesis of oral squamous cell carcinoma. Journal of Oral Science. 2016; 58:9.

47. Oztas E, Kara H, Kara ZP, Aydogan MU, Uras C, Ozhan G. Association Between Human Telomerase Reverse Transcriptase Gene Variations and Risk of Developing Breast Cancer. Genet Test Mol Biomarkers. 2016; 20:459_ 464.

48. Xing YL, Liu F, Li JF, Lin JC, Zhu GD, Li M, Zhang CR, Niu YY. Case-Control Study on Impact of the Telomerase Reverse Transcriptase Gene Polymorphism and Additional Single Nucleotide Polymorphism (SNP)- SNP Interaction on Non-Small Cell Lung Cancers Risk in Chinese Han Population. J Clin Lab Anal. 2016; 30:1071-1077.

49. Xiao X, He W. Genetic polymorphisms in the TERTCLPTM1L region and lung cancer susceptibility in Chinese males. ONCOLOGY LETTERS. 2017; 14:6.

50. Yuan X, Cheng G, Yu J, Zheng S, Sun C, Sun Q, Li K, Lin Z, Liu T, Li P, Xu Y, Kong F, Bjorkholm M, Xu D. The TERT promoter mutation incidence is modified by germline TERT rs2736098 and rs2736100 polymorphisms in hepatocellular carcinoma. Oncotarget. 2017; 8:23120-23129. https://doi. org/10.18632/oncotarget.15498. 